\title{
PASSOS PARA UMA ABORDAGEM EVOLUCIONÁRIA DO DIREITO
}

\author{
STEPS TOWARDS AN EVOLUTIONARY APPROACH TO LAW
}

\author{
Julio Cesar de Aguiar*
}

\begin{abstract}
RESUMO: o artigo apresenta algumas ideias fundamentais para o desenvolvimento de uma abordagem evolucionária do direito, baseada no conceito behaviorista radical de sistema social como rede de padrões comportamentais entrelaçados. Depois de discutir os três níveis de seleção comportamental, a saber, filogenético, ontogenético e sociocultural, o artigo explica como a emergência de um sistema jurídico funcionalmente especializado baseado em organizações jurídicas foi capaz de internalizar o processo de evolução do direito por meio da seleção das normas jurídicas mediante contingências jurídicas de segundo grau.
\end{abstract}

PALAVRAS-CHAVE: Behaviorismo radical. Contingência social de segundo grau. Seleção sociocultural. Sistema social.

ABSTRACT: The article puts forward some fundamental ideas for the development of an evolutionary approach to law based on the radical behaviorist concept of a social system as a web of interlocked behavioral patterns. After discussing the three levels of behavioral evolution, namely phylogenetic, ontogenetic and sociocultural, the article explains how the emergence of a functionally specialized legal system based on legal organizations was able to internalize the process of legal evolution through the selection of legal norms by means of second-order legal contingencies.

KEYWORDS: Radical behaviorism. Second-order social contingency. Social system. Sociocultural selection.

\section{INTRODUÇÃO}

A consolidação como alternativa teórica viável de uma abordagem evolucionária do direito enquanto sistema social é uma das mais recorrentes promessas não cumpridas da teoria social em geral e da teoria sociológica do direito em particular. Não que escasseiem propostas nesse sentido, oriundas de diferentes correntes de pensamento. O problema é que, devido a fatores diversos, dentre os quais eu destacaria o apego demasiado a um modelo evolucionário abstrato, derivado da teoria neodarwiniana da evolução biológica, e, principalmente, a falta de um mecanismo psicossociológico plausível para a seleção sociocultural, tais trabalhos têm falhado em responder às questões mais fundamentais da evolução social humana, tais como as causas da existência de sistemas sociais especializados como a ciência, a política, a

\footnotetext{
* Mestre em Filosofia pela UFG, doutor em Direito pela UFSC, PhD in Law pela University of Abedeen, UK. Professor da Graduação e do Mestrado em Direito da UCB.E-mail: juliocesar.deaguiar@gmail.com Revista da Faculdade de Direito - UFPR, Curitiba, vol. 60, n. 1, jan./abr. 2015, p. 9-38.
} 
economia e o próprio direito, e o modo como a evolução macrossociológica se combina com os padrões comportamentais dos indivíduos, para citar apenas aquelas questões que mais de perto interessam ao tema deste estudo. O presente artigo propõe alguns fundamentos teóricoconceituais os quais visam a superar os principais entraves ao desenvolvimento de uma abordagem evolucionária do direito como sistema social. A base teórica principal do artigo é uma versão do behaviorismo radical de Skinner, especialmente adaptada às necessidades de uma teoria do comportamento social humano enquanto comportamento individual e dos sistemas sociais enquanto resultado do entrelaçamento dos padrões comportamentais individuais humanos dispersos no tempo e no espaço.

A estrutura do artigo é a seguinte: uma primeira seção, dividida em três seções, secundárias, apresenta um modelo de evolução social baseado no paradigma skinneriano da seleção pelas consequências. Cada seção secundária da primeira seção é dedicada, respectivamente, a um nível de seleção do comportamento humano, a saber, filogenético, ontogenético e sociocultural. Uma segunda seção, dividida em duas seções secundárias, discute o sistema jurídico moderno enquanto ambiente social resultante da evolução e diferenciação dos sistemas sociais funcionalmente especializados. Nessa segunda seção, a primeira seção secundária trata da função social do direito. A segunda, do controle punitivo do comportamento humano. A terceira seção discute a seleção das normas jurídicas. Uma seção final resume então as principais conclusões do estudo.

\section{UM MODELO DE EVOLUÇÃO SOCIAL HUMANA}

Nas últimas décadas, o paradigma para as várias teorias da evolução social humana tem sido o esquema epistemológico proposto pelo psicólogo norte-americano Donald T. Campbell, segundo quem as explicações ou teorias científicas evolucionárias se caracterizariam pela conjugação de três processos naturais - variação, seleção e retenção -, ou, mais sinteticamente, variação mais retenção seletiva (CAMPBELL, 1974). Dentre as virtudes da proposta de Campbell, podemos citar a capacidade de descrever muito bem, em um plano abstrato, os elementos epistemológicos básicos do paradigma neodarwinista em biologia e a superação definitiva de qualquer conotação teleológica na descrição dos processos evolucionários, assim denominados para se distinguir a moderna visão científica neodarwiniana das antigas concepções evolucionistas, marcadas pela teleologia (VAN PARIJS, 1981; TEUBNER, 1988). Não obstante, uma limitação importante do modelo de Campbell é a natureza meramente analógica sugerida por ele para o relacionamento entre os 
níveis filogenético, ontogenético e cultural da evolução humana. Como consequência, os adeptos do modelo campbelliano desinteressaram-se em discutir a plausibilidade biológicoevolutiva do mecanismo psicológico proposto como base para a seleção sociocultural, resultando na proliferação de teorias meramente especulativas sobre a evolução social (VAN PARIJS, 1981; BAUM, 2001; PALMER, 1997, 2000).

Bem menos conhecido é o paradigma desenvolvido pelo também psicólogo norteamericano B. F. Skinner, que, sem contradizer na essência o esquema proposto por Campbell, enfatiza o que ele chamou de o novo modelo causal da seleção pelas consequências (SKINNER, 1976, 1981), ou seja, a relação de causalidade entre a frequência relativa de um determinado padrão comportamental no repertório de um ou mais indivíduos e as consequências decorrentes de tal comportamento para o indivíduo ou grupo de indivíduos em questão (BAUM, 2005). De acordo com o modelo skinneriano, a distinção entre os três níveis evolucionários - filogenético, ontogenético e sociocultural - dar-se-ia em função dos diferentes tipos de relações causais - ou contingências, no jargão de Skinner - incidentes sobre o padrão comportamental em foco. Assim, quando se trata de contingências de sobrevivência ou reprodução de uma população de indivíduos ao longo de várias gerações, temos o nível filogenético; quando é o caso de contingências de reforço ou punição de padrões comportamentais de um único indivíduo durante o tempo de vida deste, temos o nível ontogenético; finalmente, quando se trata de contingências de sobrevivência e reprodução de grupos humanos ocasionando o controle desses grupos sobre o comportamento dos seus membros, temos o nível sociocultural (SKINNER, 1981).

Ao longo desta seção, eu irei discorrer sobre os três níveis da seleção comportamental humana, passando rapidamente pelo nível filogenético, analisando em detalhes o nível ontogenético, e chegando finalmente ao nível sociocultural, quando então apresentarei o meu modelo de seleção sociocultural, a ser desenvolvido em detalhes na seção seguinte, focada no sistema social do direito.

\subsection{SELEÇÃO FILOGENÉTICA}

Embora seja inviável para o não especialista resumir o acervo de conhecimentos da moderna biologia evolutiva, é possível se dar uma ideia geral razoável do núcleo dessa disciplina, consistente basicamente na chamada síntese evolucionária moderna (MAYR, 1998, 2002; DAWKINS, 1989; WILLIAMS, 1992). Seguindo Baum (2005), podemos descrever o processo de seleção natural nos seguintes termos: dada uma população de indivíduos da 
mesma espécie submetida às mesmas contingências de sobrevivência e reprodução, aqueles indivíduos possuidores de características hereditárias que permitam uma maior adaptação a tais contingências tenderão a deixar um número maior de descendentes, aumentando destarte a presença das respectivas características hereditárias (e todas as demais não conflitantes com as primeiras) nas gerações seguintes, assim prosseguindo enquanto perdurarem as mesmas contingências de sobrevivência e reprodução ou não surgirem, via mutações, por exemplo, outras características hereditárias ainda mais adaptativas do que as até então predominantes.

Um exemplo clássico de seleção natural é o da mariposa Biston betularia. Até meados do século XIX, os indivíduos dessa espécie de mariposa, comum no Reino Unido, eram praticamente monomórficos, ou seja, idênticos na aparência, com o corpo coberto de escamas claras salpicadas de pintas pretas (GRANT, 1999). Uma percentagem bem menor de indivíduos, porém, apresentava uma aparência diferente de coloração uniformemente negra. A partir de certo momento, coincidindo com um incremento muito grande no número de fábricas movidas a carvão do Reino Unido, em regiões como a da cidade de Manchester, houve uma inversão na população relativa de mariposas daquela espécie, de forma que as de coloração negra passaram de raras a muito comuns, ao passo que, com as claras salpicadas de negro, ocorreu exatamente o oposto. Mais recentemente, coincidindo novamente com uma mudança nas condições ambientais, nesse caso a significativa diminuição da poluição do ar pela fuligem das fábricas, as mariposas de coloração clara voltaram a ser as mais comuns. Qual a razão dessas mudanças?

A explicação, baseada na seleção natural, é que, como as mariposas desta espécie costumam pousar com as asas abertas nos troncos das árvores, a coloração clara, inicialmente predominante, era mais favorável à sobrevivência e reprodução da espécie, em razão de assemelhar-se à cor dos troncos de árvores normalmente cobertos de líquens, dificultando assim a ação dos predadores. Com a industrialização acelerada, a fuligem das fábricas fez diminuir drasticamente a população de líquens, expondo assim a cor escura das árvores, tornando agora muito mais visíveis aos predadores - basicamente pássaros - os indivíduos de coloração clara, ao mesmo tempo que favorecia os de coloração escura, tornados menos perceptíveis aos predadores (MAJERUS, 1998). Com a diminuição da poluição, os líquens voltaram e, com eles, as mariposas de coloração clara com pintas pretas. 


\subsection{SELEÇÃO ONTOGENÉTICA}

O processo de seleção comportamental ontogenética, também conhecido como seleção ou aprendizagem operante, foi descoberto por Skinner na década de trinta do século passado (SKINNER, 1938). A partir de então, desenvolveram-se inúmeras pesquisas, primeiramente apenas com animais e com objetivos predominantemente teóricos, e posteriormente com seres humanos, com fins teóricos e terapêuticos, dando origem atualmente a pelo menos duas subdisciplinas no âmbito da psicologia - a análise experimental do comportamento e a análise comportamental aplicada -, além de várias incursões pelas ciências sociais e humanas, a começar pelos trabalhos pioneiros e revolucionários do próprio Skinner (SKINNER, 1953, 1957, 1969, 1971, 1976, 1978, 1989; CATANIA, 1998; BAUM, 2005; DONAHOE; PALMER, 2004; MICHAEL, 2004; MOORE, 2008; MALOTT, 2009; SCHNEIDER, 2012).

Com base no mesmo esquema expositivo usado na caracterização da seleção filogenética, podemos descrever a seleção comportamental ontogenética ou seleção operante da seguinte forma: dado um repertório comportamental individual, aqueles padrões comportamentais reforçados positiva ou negativamente em determinado contexto tenderão a permanecer e mesmo aumentar sua participação relativa no referido repertório, ao passo que os padrões comportamentais não reforçados tenderão a diminuir sua participação ou mesmo extinguir-se. Antes de prosseguir na explicação propriamente dita, deixe-me ilustrar a descrição proposta com dois exemplos.

Digamos que um rato faminto é posicionado em um aparato experimental em forma de caixa, com uma pequena alavanca em uma de suas paredes e, ao lado desta, um dispensador de comida acionável mecanicamente conforme previamente programado pelo experimentador. Depois de habituar-se a tal ambiente, o animal eventualmente pressiona a alavanca, ocasião em que o mecanismo dispara e uma pequena pelota de comida é depositada no dispensador, a qual é imediatamente devorada pelo rato. Conforme observado milhares de vezes por psicólogos experimentais em todo o mundo, desde que o comportamento de pressionar a alavanca seja seguido consistentemente pela oportunidade de comer, a frequência de tal comportamento irá aumentar rapidamente, superando, em muitas vezes, o valor observado no mesmo animal quando a contingência entre tal comportamento e o acesso à comida não existia (SKINNER, 1938; RACHLIN, 1991). De fato, se, depois de estabilizada uma frequência razoavelmente alta do comportamento de pressionar a alavanca, o acesso à comida for interrompido, ou seja, não mais se seguir ao pressionamento, observar-se-á uma 
progressiva redução da frequência do referido comportamento, até atingir níveis idênticos ou mesmo inferiores aos observados previamente à instituição da contingência. Passemos agora ao segundo exemplo.

Digamos que um homem fora contratado para trabalhar em um escritório cuja gerente estava sempre a repreendê-lo por qualquer coisa. Uma bela manhã, ele estava com um ramo de flores que comprara para uma amiga nas mãos, quando a gerente o surpreendeu com a fala: "Que flores lindas, para quem são?" O homem, então, por impulso, mentiu: "São para a senhora, que bom que gostou!" Naquele dia, não houve repreensões. No dia seguinte e nos próximos, o homem levou bombons, um pote de frutas em conserva e outros mimos, sempre com o mesmo resultado. Com o tempo, ele percebeu que não precisava ser todo dia, bastava que regularmente, de tempos em tempos, os presentes fossem dados, e nunca mais nosso herói precisou enfrentar as repreensões da gerente.

Em ambos os exemplos, temos o que, no jargão do behaviorismo radical de Skinner, é chamado de aprendizagem ou seleção operante por meio do reforço (DONAHOE; PALMER, 2004). Vamos por partes.

Reforço, no caso, significa a relação entre, de um lado, a apresentação de uma consequência - respectivamente, a oportunidade de comer e a cessação das repreensões contingente à realização de um dado padrão comportamental, e, de outro, o aumento da frequência do comportamento em questão no repertório do agente (CATANIA, 1998). A consequência que induz o aumento da frequência de um comportamento tornado contingente à sua ocorrência é chamada de reforçador.

O aumento da frequência de um padrão comportamental no repertório de um indivíduo como resultado da aprendizagem operante pode ser considerado um processo de seleção análogo ao da seleção natural em razão de haver uma competição entre os diversos padrões comportamentais pelos recursos do indivíduo; em particular, o esforço e o tempo despendidos por ele na realização de um comportamento em um dado contexto (BAUM; RACHLIN, 1969; BAUM, 1997, 2001, 2005). De fato, no exemplo do rato, para que o comportamento de pressionar a alavanca aumentasse em termos absolutos, foi necessário que a frequência de outros comportamentos incompatíveis diminuísse. Da mesma forma, o comportamento de comprar presentes para a gerente do escritório teve de competir com outros comportamentos que antes tomavam o tempo e o esforço do funcionário recém-contratado.

Além da relação contingente entre padrão comportamental e consequência reforçadora, a seleção operante depende também de duas outras variáveis, a saber, o contexto e a motivação. No caso do rato, o contexto que ocasiona o comportamento de pressionar a 
alavanca é o aparato experimental, e a motivação é a privação de comida a que foi submetido previamente ao experimento. No caso do funcionário do escritório, as variáveis em questão são, respectivamente, o escritório - incluindo a gerente - e as constantes repreensões.

É possível se testar experimentalmente a importância do contexto para a seleção operante, introduzindo-se no ambiente um elemento conspícuo, o qual possa ser manipulado pelo experimentador. Por exemplo, pode-se introduzir um alto-falante no aparato experimental, que emite um som quando a contingência entre pressionar a alavanca e receber a comida está em vigor, porém, permanece silencioso quando tal contingência é interrompida. Nessas condições, verifica-se que o rato continuará pressionando com grande frequência a alavanca, apenas quando o som estiver presente, mas não quando houver silêncio (PEAR, 2001). Podemos igualmente fazer um experimento mental no caso do funcionário; por exemplo, transferindo-o para outro departamento, no qual também exista uma gerente implicante. Desta vez, contudo, ao tentar evitar as constantes repreensões da gerente com o mesmo comportamento de presentear, nosso herói fracassa, pois as admoestações continuam. Provavelmente, após algumas tentativas fracassadas, ele irá cessar o comportamento de presentear. Não obstante, se retornado ao antigo departamento, é possível que o comportamento seja retomado, caso obtenha o mesmo resultado de antes. Como se vê, o contexto sinaliza ao agente em quais situações o comportamento irá ou não resultar na consequência reforçadora (MICHAEL, 1982).

Enquanto se diz que o contexto sinaliza a ocasião em que o comportamento resultará na consequência reforçadora, a motivação aumenta ou diminui o próprio efeito reforçador da consequência (MICHAEL, 1982, 1993), em uma dada ocasião. Por exemplo, no caso do rato, é a condição de estar privado de comida que torna a consequência acesso à comida reforçadora no contexto temporal do experimento. As privações em geral têm esse efeito de predispor o agente a se comportar das maneiras que, no passado, levaram-no a obter acesso à coisa de que foi privado. São exemplos, além da privação de comida, as de água, sexo, descanso, exercício, entre outras.

Já no exemplo do funcionário, temos o que no jargão behaviorista se chama de estimulação aversiva condicionada - no caso, as repreensões da gerente. A estimulação aversiva é um tipo de motivação que induz o agente a se comportar dos modos que, no passado, levaram-no a evitar ou fazer cessar tal estimulação (SKINNER, 1953). Exemplos de estimulação aversiva primária ou incondicionada são, entre outros, a dor, o frio e o excesso de calor. 
A seleção comportamental operante pode ser resultante não só do reforço, mas também da punição. Por exemplo, digamos que seja introduzida no experimento descrito acima a seguinte modificação: durante uma primeira fase do experimento, tanto com o som presente quanto ausente, o pressionamento da alavanca é seguido de comida, fazendo com que, em ambos os casos, o comportamento de pressionar a alavanca se torne frequente. Em uma segunda fase, quando o som está presente, a contingência entre pressionamento da alavanca e acesso à comida permanece como na primeira fase. Já quando o som está ausente, conjuntamente com a liberação da pelota de comida, o animal é submetido a um leve choque elétrico, por meio de uma grade eletrificada introduzida no chão do aparato experimental. Temos então, nesse segundo contexto, duas consequências do pressionamento conjugadas, o acesso à comida e o choque elétrico. Provavelmente, o rato irá reduzir significativamente o comportamento de pressionar a alavanca quando o som estiver ausente. Ele continuará pressionando com praticamente a mesma frequência da primeira fase, entretanto, quando o som estiver presente. A este tipo de consequência que produz o efeito de diminuição de um comportamento que, não fora por tal consequência, seria muito frequente em um dado contexto, dá-se o nome de punidor, e chama-se punição à respectiva contingência.

No caso do funcionário, pode-se, novamente, imaginar uma contingência punitiva análoga. Digamos que ele começasse a namorar uma colega de escritório que, por ciúmes, brigasse com ele sempre que o visse entregando presentes à gerente. A conjugação das duas consequências do comportamento de presentear a gerente levaria, provavelmente, a uma significativa diminuição de tal comportamento, sempre que a namorada estivesse presente.

Passemos agora à terceira forma de seleção comportamental humana.

\subsection{SELEÇÃO SOCIOCULTURAL}

Para introduzir a temática da seleção sociocultural, comecemos por visitar um colega mais velho do nosso funcionário em sua casa (dele, colega) à noite, no primeiro dia do mês. Vamos encontrá-lo ao lado da esposa dona de casa, conferindo as contas do mês. Lá estão a conta do aluguel, do supermercado e do plano de saúde. Comportamentos como o de ter e sustentar uma esposa, fazer compras no supermercado e alugar uma residência podem ser explicados, no plano individual, com base em contingências de reforço mantidas por reforçadores primários como sexo, comida e abrigo, respectivamente. Tais reforçadores, por sua vez, podem ter a sua capacidade de reforçar determinados comportamentos explicada pelas contingências de sobrevivência e reprodução da espécie. Como explicar, entretanto, que 
obtenhamos comida por meio da compra e não simplesmente adentrando o supermercado e pegando os alimentos de que necessitamos? Como explicar que paguemos para ter abrigo, em vez de simplesmente invadir os prédios e nos instalarmos neles? Como explicar que obtenhamos sexo por meio de relações consensuais e não pela força? As respostas a tais perguntas giram em torno da existência de contingências de reforço e punição mantidas pelos grupos humanos para controlar o comportamento dos respectivos membros, chamadas, no jargão skinneriano, de práticas culturais (SKINNER, 1971, 1976, 1981, 1988; LAMAL, 1991; BAUM, 2005). A seleção dessas práticas culturais é o objeto da teoria da seleção sociocultural que eu irei apresentar suscintamente nesta seção.

Procurando manter a mesma estrutura das descrições anteriores dos níveis filogenético e ontogenético de seleção comportamental humana, podemos descrever a seleção sociocultural nos seguintes termos: dado um grupo humano, as práticas culturais que possibilitem uma melhor adaptação às contingências de sobrevivência e reprodução do grupo como um todo tenderão a predominar em detrimento das práticas culturais alternativas menos adaptativas.

Uma importante premissa do modelo de Skinner (1981, p. 502) da evolução sociocultural é a de que "[i]t is the effect on the group, not the reinforcing consequences for individual members, which is responsible for the evolution of the culture". Por outro lado, como enfatizam Baum (2001) e Skinner (1953), são os indivíduos e não os grupos como entidades supraindividuais atuantes que, por meio de repertórios comportamentais especializados, sustentam as práticas culturais. Como conciliar essas duas premissas aparentemente contraditórias? A resposta, que desenvolveremos a seguir com base nas ideias lançadas por Skinner - principalmente no livro Verbal Behavior (SKINNER, 1957) e nos oito capítulos que compõem as seções IV e V do clássico Science and Human Behavior (SKINNER, 1953) -, está no conceito behaviorista radical de sistema social.

Podemos definir sistema social como uma rede de padrões comportamentais entrelaçados (interlocked behavioral patterns), em que cada padrão comportamental serve de contexto e fonte de reforço ou punição para o outro e vice-versa. O sistema social mais simples é a interação social, que tem por característica a dependência da copresença dos respectivos participantes para a existência do sistema (LUHMANN, 1990). Os exemplos mais comuns de interação social são díades, como a conversa casual entre duas pessoas, denominada evento verbal por Skinner (1957).

Um tipo de sistema social fundamental na evolução da sociedade moderna é a organização. Uma organização ou sistema social organizado surge quando um fundador ou 
líder controla, por meio de reforçadores ou punidores, o comportamento de outros indivíduos, com vistas a um fim de seu interesse (SKINNER, 1953). O exemplo típico são as organizações econômicas ou firmas. Em todos os tipos de organizações, as contingências que controlam o comportamento do fundador ou líder são normalmente distintas das que controlam o comportamento dos demais membros. Assim, em uma firma, o comportamento do proprietário ou proprietários é controlado pelas contingências, principalmente econômicas, que determinam o lucro da firma, ao passo que o dos empregados é controlado pelo pagamento dos salários.

A organização moderna, portanto, é um sistema social constituído pelo controle exercido pelo seu líder ou fundador sobre o comportamento organizado dos demais membros da organização com base em um reforçador como, por exemplo, o dinheiro. Porém, uma vez formada, a organização adquire o controle sobre um novo reforçador ou punidor, a saber, o produto do comportamento organizado dos seus membros, o qual é capaz então de respectivamente reforçar ou punir o comportamento de pessoas externas à organização, cujo comportamento, por sua vez, reforça ou pune o comportamento do líder ou fundador da organização (GLENN; MALOTT, 2004). Por exemplo, nas firmas, tais produtos são bens ou serviços; nos órgãos governamentais, bens públicos, como segurança e justiça, e assim por diante.

A sobrevivência das organizações depende, então, em última instância, da manutenção dessa capacidade de reforçar ou punir o comportamento de pessoas externas a elas. Disso decorre a característica desses sistemas sociais de serem orientados a objetivos (MALOTT, 2003, 2009). Assim, embora em uma firma ocorram diariamente vários tipos de comportamentos sociais, apenas alguns deles podem ser classificados como simples interações - por exemplo, o encontro entre empregados nos intervalos para o cafezinho. A grande maioria, ao contrário, compõe padrões comportamentais entrelaçados que, para serem explicados, dependem da análise da relação instrumental entre tais padrões e a obtenção e manutenção do controle sobre o comportamento de pessoas externas que constitui o objetivo ou meta da organização. Por exemplo, as rotinas e procedimentos de uma firma prestadora de serviços alimentícios, que constituem padrões comportamentais entrelaçados, dependem, para sua sobrevivência, da manutenção do comportamento dos clientes de utilizarem os serviços da firma, reforçando assim o comportamento do proprietário da firma de pagar os empregados para prestarem tais serviços aos clientes.

A manutenção dos padrões comportamentais entrelaçados que compõem o ambiente social tanto interno quanto externo das organizações pode ser em muito facilitada pela Revista da Faculdade de Direito - UFPR, Curitiba, vol. 60, n. 1, jan./abr. 2015, p. 9-38. 
utilização de regras. No jargão behaviorista, regras são padrões comportamentais verbais que descrevem uma contingência comportamental - basicamente, se você fizer tal coisa em tal contexto, seguir-se-á tal reforçador ou punidor; razão pela qual são muito úteis ao aprendizado mais rápido de comportamentos por parte dos destinatários de tais regras, ao mesmo tempo que são úteis aos formuladores de regras no sentido de garantir um maior controle sobre o comportamento dos respectivos destinatários (BAUM, 1995, 2005; GLENN, 1987; SKINNER, 1969, 1976, 1989).

O fato de as organizações se especializarem na produção de determinado tipo de reforçador ou punidor (mercadorias, serviços, saúde, justiça, segurança, entre outros) faz delas o fator fundamental para a emergência de um terceiro tipo de sistema social - o mais importante para o tema deste artigo -, a saber, os sistemas sociais funcionalmente especializados, ou simplesmente, sistemas funcionais, entre os quais figura o direito.

Um sistema social funcionalmente especializado emerge quando os padrões relativamente estáveis de influência comportamental recíproca entre determinadas organizações e os indivíduos que compõem o seu público-alvo se especializam no cumprimento de uma importante função para a sobrevivência e reprodução do grupo social como um todo, em um dado contexto espaço-temporal. $\mathrm{O}$ exemplo clássico é a economia. Segundo a descrição simplificada dos economistas, o sistema econômico é composto basicamente pelos padrões comportamentais entrelaçados de famílias (indivíduos) e firmas (organizações) mediados pelo (reforçador generalizado) dinheiro (MANKIW, 2008).

As sociedades contemporâneas são compostas predominantemente pelos sistemas sociais funcionais especializados (LUHMANN, 1995), com destaque para os sistemas econômico, político, jurídico, científico e educacional (RODRÍGUEZ; ARNOLD, 2007). Não se trata, porém, de vários processos isolados que culminaram nas sociedades funcionalmente diferenciadas que temos hoje, mas de um processo historicamente integrado de diferenciação das sociedades em sistemas que são, ao mesmo tempo, funcionalmente distintos, porém, interligados e dependentes uns dos outros (LUHMANN, 1982; MOELLER, 2006).

Não é possível, nos limites deste artigo, discutir sequer minimamente esse processo. Vou me limitar, então, a postular que a chave para a compreensão teórica do processo histórico-evolutivo de diferenciação funcional é o que Teubner $(1988,1993)$ chamou de internalização do ambiente selecionador pela sociedade, o que, em termos behavioristas, pode ser interpretado como a capacidade que os sistemas sociais funcionalmente especializados adquiriram, de servirem como objetos da e, simultaneamente, ambientes responsáveis pela seleção sociocultural humana. No restante desta seção, eu irei explicar sucintamente em que 
consiste tal processo de internalização e qual a sua ligação com a diferenciação da sociedade em sistemas sociais funcionalmente especializados.

Como vimos acima, a seleção sociocultural pressupõe a maior adaptabilidade das práticas culturais selecionadas às contingências de sobrevivência e reprodução dos grupos humanos. Em um estágio inicial do processo evolucionário sociocultural, é plausível imaginarmos que as práticas culturais menos adaptativas tenham perecido juntamente com os grupos que as adotavam (BAUM, 2001), mais ou menos como proposto pelos adeptos do modelo dito sociobiológico de evolução das culturas humanas (MAYNARD SMITH, 1982). Independentemente, porém, das controvérsias sobre a viabilidade ou não da seleção grupal no nível sociobiológico (SOLTIS; BOYD; RICHERSON, 1995; WILSON, 2006), o fato é que, desde há muito na história humana, a seleção sociocultural tem se caracterizado pela seleção de práticas culturais por processos que não implicam o perecimento (extinção) de sociedades ou grupos sociais (CAMPBELL, 1974; SKINNER, 1988; HARRIS, 1990; BAUM, 2001). Ou seja, a partir de determinado momento da história humana, a sobrevivência e reprodução das sociedades humanas passou a depender fundamentalmente da substituição de práticas culturais menos adaptativas por outras mais adaptativas no interior da própria sociedade, isto é, por intermédio de processos seletivos internos a essas sociedades (TEUBNER, 1993).

Cabe lembrar que, segundo a definição dada acima, práticas culturais nada mais são do que contingências de reforço e punição de comportamentos individuais impostas pela sociedade, ou seja, por meio de outros comportamentos individuais. Isso significa que o processo internalizado de seleção das práticas culturais ora em análise deve ser constituído, ele próprio, de contingências sociais de reforço e punição de comportamentos individuais, razão pela qual podemos chamar as contingências responsáveis pela seleção das práticas culturais de contingências sociais de segundo grau, no sentido de contingências sociais selecionadoras de outras contingências sociais. É exatamente na constituição deste duplo processo de seleção comportamental que entra o papel fundamental das organizações e seus respectivos públicos-alvo. Senão vejamos.

Vimos anteriormente que um elemento fundamental na estabilização das redes de comportamentos entrelaçados que constituem as organizações, tanto internamente quanto no seu relacionamento com os respectivos públicos-alvo, são as regras. Podemos, então, para simplificar a análise, abstrair momentaneamente os demais elementos das contingências sociais e raciocinar em termos apenas de regras. Diremos assim que as práticas culturais são constituídas basicamente por regras que controlam os comportamentos de seus destinatários (BAUM, 1995, 2001). Por exemplo, uma norma penal como o homicídio (artigo 121 do 
Código Penal Brasileiro) é uma prática cultural, no sentido de controlar o comportamento das pessoas sob a jurisdição penal brasileira. Ora, partindo da ideia de contingência social de segundo grau explicada acima, podemos dizer que a seleção das normas penais, enquanto práticas culturais, dá-se por intermédio de normas penais de segundo grau, ou seja, regras que controlam a seleção de normas jurídico-penais (PATERSON; TEUBNER, 1998; PATERSON, 2009). Da mesma forma, se, seguindo autores como Baum, Skinner e outros, entendermos as chamadas leis científicas como regras para a manipulação eficaz do ambiente natural (SKINNER, 1969; ROSSI, 1962; BAUM, 2001; MOORE, 2008), poderemos concluir que os princípios metodológicos e epistemológicos, bem como as regras do raciocínio lógico dedutivo e indutivo, são leis ou regras científicas de segundo grau, isto é, regras para a seleção de práticas culturais científicas (SKINNER, 1957, 1969).

Com base nas ideias acima, eu quero postular agora - sem mais justificativas, dadas as limitações de espaço de um artigo como este -, primeiro, que o processo de especialização funcional coincide, de um lado, com a emergência de organizações voltadas ao cumprimento de determinadas funções sociais; e, de outro, com o desenvolvimento de regras para a seleção de regras em cada um dos subsistemas sociais formados por essas organizações especializadas e seus respectivos públicos-alvo. Segundo, que esse processo de internalização da seleção das práticas culturais por meio da especialização funcional cria uma dinâmica evolucionária dupla, correspondente, por uma parte, à seleção dos comportamentos individuais pelas práticas culturais (contingências sociais de primeiro grau); e, por outra parte, à seleção das próprias práticas culturais, via contingências sociais de segundo grau.

Cabe frisar que, sendo a enunciação de regras uma forma de comportamento verbal que, conforme explicado acima, descreve uma contingência de reforço ou punição, segue-se que a própria manutenção dos comportamentos de instituir e seguir regras, sejam elas de primeiro ou segundo grau, depende em última instância da precisão com que tais regras descrevem as respectivas contingências (SKINNER, 1969). Em outras palavras, de um lado, o destinatário das regras irá segui-las ou não, dependendo de se estas o auxiliam ou não a obter o reforço ou evitar a punição descrita nas mesmas. De outro lado, a manutenção do comportamento de enunciar uma regra irá depender de se os respectivos destinatários reforçam ou não tal comportamento por parte do enunciador, principalmente, por meio do seguimento ou obediência à regra (BAUM, 2005).

Nas próximas seções, eu irei aplicar ao sistema jurídico essas ideias, por ora ainda bastante abstratas, sobre a seleção sociocultural. 


\section{O DIREITO COMO AMBIENTE SOCIAL SELECIONADO E SELECIONADOR}

Vimos na seção anterior que a seleção sociocultural opera por intermédio de dois processos evolucionários conjugados: o primeiro, responsável pela seleção dos comportamentos individuais, por meio de práticas culturais, e o segundo, pela seleção das próprias práticas culturais.

Vimos também que esses dois processos evolucionários constituem o elemento fulcral do processo de especialização funcional dos sistemas sociais modernos, como o direito, a economia e a ciência, tendo sido mencionado de passagem que tais funções sociais correspondem ao que Skinner denomina efeitos dos comportamentos individuais para o grupo como um todo, correspondendo, portanto, às contingências de sobrevivência e reprodução dos grupos humanos, responsáveis, em última instância, pela seleção sociocultural (SKINNER, 1981). Na primeira seção secundária desta seção, eu irei tentar então responder a uma questão preliminar sobre o processo de evolução do direito, a saber: em que consiste a função social das práticas culturais a que denominamos normas jurídicas? E, na segunda seção secundária, eu irei descrever com algum detalhe o processo de controle comportamental por meio das normas jurídicas.

\subsection{A FUNÇÃO SOCIAL DO DIREITO}

De acordo com a definição dada acima, o primeiro passo para definirmos qual a função social do direito é identificar que tipo de prática cultural, ou seja, que tipo de controle do comportamento individual exercido pelo grupo, é o direito. Segundo Skinner, o direito é basicamente controle social do comportamento individual por meio de punições (SKINNER, 1989). O mesmo autor observa também que o direito não é o único sistema social que se baseia no controle punitivo, havendo outros, dentre os quais ele destaca o controle religioso e o que ele chama de controle ético do grupo; de forma muito semelhante, diga-se de passagem, à de teóricos do direito consagrados, como Hans Kelsen (1945) e Niklas Luhmann (1985).

O direito, no entanto, teria se tornado o mais importante meio de controle social punitivo em razão da sua maior estabilidade e previsibilidade, decorrentes ambas do fato de as organizações estatais terem assumido a tarefa de controlar os indivíduos por meio de punições, instituindo para tanto normas jurídicas, as quais foram as principais responsáveis, segundo Skinner (1953), pela superioridade do direito frente às outras formas competidoras de controle social punitivo. Não obstante, caberia acrescentar ainda a essas duas vantagens competitivas do direito a sua maior adaptabilidade, ou seja, a possibilidade de as normas 
jurídicas, especialmente na sua forma positiva moderna, mudarem de acordo com as transformações ocorridas nas contingências de sobrevivência e reprodução do grupo, aumentando assim a aptidão da comunidade como um todo (LUHMANN, 1985).

Definido o direito como controle social punitivo e explicada a sua predominância em face das outras formas desse controle, a próxima etapa para o esclarecimento da função social do direito é responder à questão: por que afinal a sociedade pune determinados comportamentos? Em outras palavras: que tipo de vantagem adaptativa a punição de determinados comportamentos traz para o grupo como um todo?

A própria estrutura da contingência punitiva fornece um começo de resposta para essa questão. Com efeito, do ponto de vista behaviorista, toda contingência punitiva é sempre sobreposta a uma contingência de reforço, a qual é responsável pela presença do comportamento punido no repertório do indivíduo (CATANIA, 1998). Não fora assim, a contingência punitiva seria ineficaz, pois o comportamento punido ou nem sequer ocorreria ou não se manteria por muito tempo no repertório do indivíduo, por falta do correspondente reforço (MALLOT, 2009). Isso fica evidente, no caso do rato do exemplo dado acima. Não fosse pela contingência reforçadora entre o comportamento de pressionar a alavanca e o consequente acesso à comida, o comportamento em questão não ocorreria e tampouco se poderia instituir a contingência punitiva entre tal comportamento e o choque elétrico.

Dito isso, é necessário ainda, para explicar a contingência social punitiva, pressupor que, em toda e qualquer sociedade, existem determinados comportamentos que são considerados socialmente indesejáveis e, não obstante, ocorrem com razoável frequência, em determinados contextos. Por socialmente indesejáveis eu quero dizer comportamentos prejudiciais à aptidão do grupo social como um todo, os quais, em razão disso, induzam, provoquem ou sirvam de ocasião para comportamentos punitivos não apenas por parte daqueles indivíduos diretamente afetados, mas também de terceiros (LUHMANN, 1985). A questão então é: como tais comportamentos prejudiciais ao grupo chegam a ser identificados como tal pela comunidade?

Como observa Durkheim (1964; LUHMANN, 1985), em sociedades pouco diferenciadas internamente, em que todos os membros tenham modos de vida muito semelhantes, não é tão difícil para o grupo chegar a um consenso sobre quais comportamentos são prejudiciais à comunidade e, por isso, devam ser punidos. Com a crescente diferenciação social, entretanto, surgem divergências de interesses que se refletem na falta de consenso jurídico. O direito passa então a ser ditado pelo subgrupo ou elite dominante no interior da sociedade (SKINNER, 1953; MALOTT, 2009; POSNER, 2003). 
Paralelamente a este processo de diferenciação social, há uma grande ampliação do rol de condutas objeto do controle social punitivo. De fato, dado que as primeiras formas de punição social dependiam do engajamento coletivo de toda ou grande parte da comunidade, os primeiros delitos restringiam-se àquelas condutas mais obviamente prejudiciais ao grupo e também mais comuns, como o furto, a lesão corporal e o homicídio (LUHMANN, 1985). Só com o advento das organizações estatais e com a assunção por elas da função punitiva, tornou-se possível aumentar significativamente o rol dos delitos e das penas, já que não se precisava mais da adesão da quase totalidade do grupo social para a aplicação da pena. Como corolário dessa transformação histórica, o direito se tornou, em muitos casos, um instrumento de dominação política e até eventualmente de opressão por parte das elites sociais sobre os demais membros da sociedade (ACEMOGLU; ROBINSON, 2012).

Se as sociedades punem, inicialmente, é porque as condutas punidas são de fato e claramente indesejáveis e prováveis; porém, com o advento da dominação estatal, porque assim o determinam as elites politicamente dominantes, como fica então a questão da função social do direito? Ora, pressuposta a imposição eficaz das contingências punitivas, é claro que a maior ou menor aptidão do grupo irá depender da percepção correta por parte da sociedade - ou de sua elite dominante - de quais condutas devam ser consideradas prejudiciais à sobrevivência e reprodução do grupo e, portanto, punidas. Esta é, na verdade, a razão de ser da especialização funcional do sistema jurídico e, consequentemente, segundo a nossa tese adiantada acima, da própria existência das contingências selecionadoras de normas jurídicas. Voltaremos a este ponto na próxima seção.

\subsection{O CONTROLE PUNITIVO DO COMPORTAMENTO INDIVIDUAL}

Muito se tem discutido sobre a real capacidade dissuasiva das punições juridicamente impostas (COTTERREL, 1992). Do ponto de vista behaviorista radical, porém, tais discussões fazem pouco ou nenhum sentido. Isso porque uma consequência imposta contingentemente a um comportamento só pode ser considerada uma punição no jargão skinneriano se e na medida em que ocasione, de fato, a diminuição da frequência do comportamento em questão no repertório do indivíduo (CATANIA, 1998). Assim definido, a existência e eficácia do controle comportamental punitivo não podem ser questionadas, por tratar-se de fatos observados incontáveis vezes em laboratórios e outros ambientes controlados, com sujeitos experimentais humanos e não humanos (MALOTT, 2009). 
É verdade que, liderados por Skinner (1953), alguns behavioristas têm feito restrições ao uso da punição para o controle terapêutico do comportamento individual (SIDMAN, 1989). Não obstante, no plano sociológico, a eliminação da punição é claramente utópica. Isso porque, como assinalado anteriormente, o pressuposto para a evolução social das práticas culturais punitivas é a ideia de que são as próprias contingências de reforço normalmente presentes na vida social que originam e mantêm os comportamentos socialmente indesejáveis punidos por tais práticas culturais (BAUM, 2005).

Por outro lado, o modelo behaviorista da seleção comportamental via contingências sociais punitivas, na medida em que permite analisar o efeito da punição juridicamente imposta em uma variada gama de comportamentos, pode ser um instrumento científico valioso para desagregar e analisar separadamente dados referentes tanto ao efeito dissuasório efetivo das sanções sobre o comportamento punido quanto ao respectivo efeito reforçador sobre o comportamento punidor, de uma forma que os modelos teóricos de sociólogos e economistas não costumam fazê-lo (LEVITT, 1996; TODOROV, 2001, 2005). Senão vejamos.

\subsubsection{O comportamento punitivamente controlado}

A punição social pode atuar sobre o comportamento individual de modo direto ou indireto. Ela atua diretamente quando é aplicada ao próprio agente que se comportou de modo socialmente indesejável. Ela atua indiretamente de duas formas principais. Primeiro, quando o indivíduo observa outro indivíduo sendo punido pela comunidade ou por representantes dela, após ter praticado determinada ação, passando então a evitar praticar o mesmo tipo de comportamento. De fato, uma característica comum ao ser humano e a muitos outros animais é a capacidade de aprender a comportar-se ou a evitar comportar-se de determinada maneira, observando o comportamento de outros animais da mesma espécie e as respectivas consequências reforçadoras ou punitivas advindas de tal comportamento (SKINNER, 1953; BAUM, 2005; SCHNEIDER, 2012). Segundo, por intermédio de punidores condicionados verbais ou por intermédio de regras. Palavras como pecado, crime, imoralidade, por estarem constantemente presentes em contextos punitivos sociais, são exemplos de possíveis punidores condicionados verbais, assim como os nomes dados às próprias condutas punidas, como assassinato, corrupção, roubo, ou ainda aos indivíduos que praticam tais condutas, por exemplo, ladrão, corrupto, assassino, e assim por diante. 
Já as regras punitivas podem ser transmitidas tanto em forma de ordem para a omissão ou prática de determinada conduta, sob a ameaça implícita de punição - como nos dez mandamentos da Lei Mosaica ou em certas placas de trânsito -, quanto sob a forma de estruturas verbais especiais, a exemplo dos tipos penais do direito brasileiro, em que o comportamento e a respectiva punição são descritos em uma forma verbal padrão que vincula a punição à prática do comportamento (SKINNER, 1953, 1989). No primeiro caso, advérbios como não, emitidos juntamente com verbos que descrevem o comportamento comissivo ou omissivo, tornam aversivos para o agente, respectivamente, o cometimento ou omissão do comportamento em questão. O mesmo sendo o caso de palavras ou símbolos indicativos de proibido fazer veiculados junto a palavras ou símbolos indicativos de algum comportamento (estacionar, por exemplo). Em relação às regras veiculadas por meio de estruturas gramaticais fixas (frames), pode-se atribuir plausivelmente, com base em evidências experimentais, um efeito aversivo condicionado a essas próprias estruturas gramaticais, de forma semelhante ao efeito aversivo de um ilogismo, por exemplo, para o indivíduo que foi punido no passado por raciocinar ilogicamente (PALMER, 1998; LOWENKRON, 1998, 2006). Tal efeito, quando circunscrito aos ambientes jurídicos profissionais, é parte do que se conhece como retórica jurídica. No entanto, qualquer pessoa de cultura mediana no Brasil sente os efeitos motivacionais característicos se posta diante de um texto com os dizeres: $O$ destinatário desta deverá comparecer ao posto da Receita Federal mais próximo e pagar a quantia abaixo, no prazo de trinta dias, sob pena de multa de $150 \%$ sobre o valor devido, mais juros e correção monetária. O mesmo vale para os textos legais estipulando penalidades para a prática ou omissão de determinada conduta, eventualmente transcritos em comunicados do tipo acima.

Em qualquer caso, a natureza condicionada dos punidores elencados acima implica a dependência do respectivo efeito aversivo para com a manutenção de uma correlação consistente entre tais elementos contextuais verbais e a aplicação de punidores incondicionados às respectivas condutas comissivas ou omissivas. Assim, se em um determinado contexto social, as palavras assassino e assassinato deixam de estar correlacionadas com uma alta probabilidade de punição, elas tendem a perder o seu caráter de punidores condicionados, o mesmo ocorrendo com as palavras executante e executado, se a cobrança judicial é ineficaz (MALOTT, 2009).

Não obstante a sua importância decisiva, o efeito motivador dos punidores condicionados, isoladamente considerados, ainda é insuficiente para descrever o controle punitivo exercido pelo direito sobre o comportamento individual. Isso porque, conforme observa Black (1976), tal controle se dá por meio de uma rede de condutas interligadas que 
intermedeiam o cometimento efetivo ou potencial do delito e a aplicação da pena propriamente dita. Entre tais condutas, incluem-se desde chamar a polícia, testemunhar em juízo, oferecer ou não uma denúncia, condenar ou não um réu, até apoiar uma proposta legislativa de tornar crime determinada conduta e assim por diante. Em outras palavras, o controle jurídico-punitivo do comportamento não é o resultado de encontros sociais isolados, ocorrendo livremente como moléculas de um fluido esbarrando umas nas outras, mas sim do que poderíamos chamar efeito sistêmico de uma rede de comportamentos entrelaçados, os quais obedecem a contingências específicas, cujo efeito agregado, entretanto, estende-se a toda a rede (TEUBNER, 1993). Embora seja possível e até eventualmente mais conveniente estudar esse efeito sistêmico em nível agregado, como o fazem rotineiramente sociólogos e economistas, apenas uma análise dos vários padrões comportamentais em separado pode elucidar os mecanismos por meio dos quais tais efeitos sistêmicos são gerados (SKINNER, 1953; HEDSTRÖM, 2005). Para discutirmos melhor esta ideia, temos de mudar o foco da análise do comportamento punitivamente controlado para o comportamento punidor, o que é o objeto do restante desta seção.

\subsubsection{O comportamento punidor}

O primeiro passo para compreender o comportamento punidor é precisamente lembrar que se trata de comportamento humano, o que pode não ser tão intuitivamente óbvio devido ao que poderíamos chamar de ilusão dualista, ou seja, a tendência que temos de pensar as normas jurídicas como entidades distintas dos comportamentos verbais e não verbais que as põem efetivamente em prática (TAMANAHA, 1996, 2000). Tal tendência é devida em grande parte ao hábito de advogados e juristas em geral de consultarem textos, principalmente legais, mas também jurisprudenciais e doutrinários, a fim de saber qual o direito aplicável ao caso, como se realmente o direito estivesse nos livros e não no repertório comportamental desses profissionais. Mesmo os adeptos do chamado realismo jurídico norte-americano não se libertaram de todo dessa ilusão, ao manterem a dicotomia entre direito nos livros versus direito em ação (DUXBURY, 1995).

Para o behaviorismo, ao contrário, existe apenas o direito em ação, sendo os livros meros elementos contextuais que auxiliam os juristas (e eventualmente os leigos) a emitirem os comportamentos adequados às diversas situações, comportamentos esses que, em grande parte das vezes, são verbais, o que explica a utilidade dos livros para os profissionais do direito (SKINNER, 1957, 1989). O controle jurídico-punitivo, porém, como já observado, 
inclui uma gama muito maior de comportamentos, verbais e não verbais, os quais, para serem compreendidos, exigem uma análise comportamental completa, ou seja, que inclua as demais variáveis, além de eventuais elementos contextuais verbais, como leis, doutrinas e precedentes jurisprudenciais. Refiro-me, claro, às variáveis comportamentais discutidas anteriormente, a saber, a motivação, o contexto e as contingências de reforço ou punição. Vejamos rapidamente cada uma delas.

O contexto funciona principalmente como variável discriminadora entre o legal e o ilegal; ou seja, certos comportamentos são legais em alguns contextos e ilegais em outros. Por exemplo, tirar a roupa dentro de sua própria casa é legal, ao passo que, na praça de alimentação de um shopping, é ilegal. Lesar fisicamente alguém é, normalmente, ilegal, mas, se for em reação a "injusta agressão, atual ou iminente, a direito seu ou de outrem", considerado legal. Em países como a Holanda, a venda de cannabis sativa para consumo não médico é, em geral, ilegal, mas, em certos locais, conhecidos como coffeeshops, é legal. O significado de tais diferenças contextuais é que comportamentos punitivos como, entre outros, chamar a polícia, prender em flagrante, registrar uma ocorrência e oferecer uma denúncia irão ocorrer, dependendo do contexto, com maior ou menor probabilidade, correspondendo aproximadamente à maior ou menor probabilidade de que tais comportamentos sejam reforçados ou não em tais contextos.

As contingências de reforço e punição são as consequências que decorrem do comportamento punitivo em determinado contexto, tornando-se então responsáveis pela probabilidade futura de ocorrência do comportamento punitivo no mesmo contexto. Por tais contingências, estou me referindo não só ao ato punitivo final, que, analogamente ao que ocorre com a cadeia de comportamentos de um animal em laboratório, reforça todos os comportamentos que compuseram a série de comportamentos encadeados que levou ao referido ato final (SKINNER, 1953; MALOTT, 2009), como também, e principalmente, ao fato de que cada elo na cadeia comportamental reforça os elos antecedentes (GLENN; MALOTT, 2004). Assim, a vítima não chama ou deixa de chamar a polícia apenas em função da probabilidade de o delito ser ao final punido, mas também em função, por exemplo, do tempo que a polícia irá levar (levou no passado) para chegar e do tipo de providência que irá tomar (tomou no passado) após a chegada ao local. Da mesma forma, o fato de que, na maioria das vezes, o registro da ocorrência policial na delegacia não surtirá (não surtiu no passado) qualquer efeito imediato, do ponto de vista de induzir as autoridades a começar

\footnotetext{
${ }^{1}$ Artigo 25 do Código Penal (BRASIL, 1940).

Revista da Faculdade de Direito - UFPR, Curitiba, vol. 60, n. 1, jan./abr. 2015, p. 9-38.
} 
imediatamente a investigar o caso, é altamente prejudicial à ocorrência do comportamento de registrar ocorrências. Contingências de reforço ou punição externas à cadeia comportamental punitiva são também importantes. Em certos casos, elas tornam mais prováveis comportamentos punitivos normalmente pouco prováveis, como a contingência que torna o ato de testemunhar obrigatório, ou, no caso das autoridades policiais e judiciais, o pagamento de salários e o correspondente dever funcional de agir. Em outros casos, ocorre o contrário, certos comportamentos punitivos muito prováveis são punidos ou não reforçados, como no chamado crime de "exercício arbitrário das próprias razões"2, ou no caso das prescrições penal e cível.

A motivação é uma variável contextual que torna reforçador um estímulo, evento ou objeto, em um dado momento, e, consequentemente, evoca os comportamentos que, no passado, tornaram tal reforçador mais provável (MICHAEL, 1983). Por exemplo, a visão de um estranho em minha sala de estar, no meio da noite, com lanterna e arma nas mãos, é um motivador que torna reforçador o evento carro de polícia estacionando em frente à minha casa e dando ordem de prisão ao meliante, aumentando destarte a probabilidade, naquele momento, do meu comportamento ligar para a polícia. Os comportamentos delituosos, em geral, motivam pela sua aversividade, como no caso do exemplo dado. A aversividade do comportamento delituoso para o agente punidor é então fundamental, já que, por tornar a punição do delinquente reforçadora - não só o ato final, mas principalmente o comportamento punitivo seguinte na cadeia comportamental que leva à punição final -, torna mais provável o comportamento punitivo, quando da ocorrência do delito.

Na próxima seção, eu irei aplicar as ideias discutidas até aqui na abordagem do problema da seleção das normas jurídicas.

\section{A SELEÇÃO DAS NORMAS JURÍDICAS}

Conforme extensamente argumentado acima, o direito é um sistema funcionalmente especializado de práticas culturais punitivas. Cada norma jurídica, então, pode ser considerada um subsistema desse sistema social englobante que é o direito. Vimos também que a seleção das normas jurídicas, assim como a de qualquer prática cultural, dá-se de forma internalizada na comunidade social, ou seja, por meio de contingências de reforço e punição de segundo grau, cujos loci privilegiados são as organizações jurídicas e seus respectivos públicos-alvo.

\footnotetext{
${ }^{2}$ Ibid., art. 345.
} 
Vamos agora desenvolver mais detalhadamente essas ideias, focando especificamente na seleção das normas jurídicas.

Como sugerido por diversos autores, pelo menos desde o limiar da era moderna, as principais organizações jurídicas têm natureza governamental, destacando-se os tribunais e órgãos legislativos (SKINNER, 1953; KELSEN, 1967; LUHMANN, 1985; POSNER, 2003). Desde a sua emergência, compete a essas organizações definir as normas jurídicas vigentes em uma dada sociedade. Em outras palavras, cabe a elas decidir quais comportamentos devem ser punidos, em que contexto e como deve ser tal punição. O que estamos chamando então de contingências de segundo grau são os elementos contextuais, motivacionais e as consequências para os indivíduos que compõem tais organizações, relacionados especificamente à definição (seleção) de tais normas jurídicas.

O material empírico para o estudo da evolução jurídica abunda na literatura sobre o direito (DURKHEIM, 1964; WEBER, 1968; WATSON, 1985; FRIEDMAN, 1985; NORTH, 1981, 1990). Meu propósito nesta seção, entretanto, não é fazer uma resenha de tal literatura, mas traçar, com base na discussão travada até aqui, alguns parâmetros teóricos para a interpretação dos dados contidos nesses estudos empíricos, de um ponto de vista sociológicoevolucionário. Mais especificamente, minha proposta é construir um modelo bastante simplificado de contingência jurídica de segundo grau, o qual poderá servir então para a investigação do estágio em que se encontra a internalização da seleção sociocultural das normas jurídicas nas diversas sociedades contemporâneas e dos modos particulares em que tal internalização está se dando em cada uma delas (TEUBNER, 1993).

\subsection{MODELO DE CONTINGÊNCIA JURÍDICA DE SEGUNDO GRAU}

As contingências jurídicas de segundo grau são, na verdade, sistemas compostos normalmente por quatro contingências comportamentais que, em conjunto, perfazem o que Skinner (1969, p. 144) denomina de "modelo do ambiente". O primeiro elemento do modelo é composto por determinados padrões comportamentais, presentes em algum setor da sociedade, juntamente com as contingências de reforço responsáveis pela emergência e manutenção desses comportamentos. O segundo elemento é o que Malott $(1989,2009)$ chama paradoxalmente de contingência ineficaz, mas que eu prefiro chamar de pseudocontingência, composta pelos mesmos comportamentos do primeiro elemento do modelo e certas consequências não imediatas desses comportamentos para o próprio agente ou terceiros, as quais se mostram prejudiciais à sobrevivência e reprodução do grupo social como um todo. 
Esse segundo elemento do modelo é denominado pseudocontingência em razão de que, ao contrário do que se dá em uma contingência comportamental verdadeira, as consequências, em decorrência de seu caráter mediato, não afetam a probabilidade de ocorrência futura dos comportamentos que lhes dão origem, não podendo, portanto, ser consideradas um exemplo de causalidade pelas consequências. O terceiro elemento do modelo é a contingência entre os resultados não imediatos dos comportamentos socialmente indesejáveis e o comportamento punidor que compõe a norma jurídica. O quarto e último elemento, então, é a norma jurídica, ou seja, uma contingência punitiva aplicada de forma sobreposta aos comportamentos pertencentes ao primeiro e segundo elementos do sistema - que podemos chamar de comportamentos socialmente indesejáveis -, visando a alterar-lhes a probabilidade de ocorrência e, assim, elidir as respectivas consequências não imediatas, prejudiciais à aptidão do grupo social. Os exemplos a seguir devem auxiliar na compreensão do modelo.

\subsection{EXEMPLOS DE CONTINGÊNCIAS JURÍDICAS DE SEGUNDO GRAU}

Praticamente a totalidade das nações modernas, o Brasil incluído, possuem leis contra a poluição ambiental, por parte, por exemplo, de indústrias que liberam no ambiente ar, rios, lagos, oceanos, etc. - todo tipo de substâncias poluentes, as quais são prejudiciais à sobrevivência e reprodução da comunidade como um todo. A emergência e manutenção (seleção) de tais leis podem ser descritas com base no modelo de contingência jurídica de segundo grau acima proposto. Senão vejamos.

Primeiramente, temos o comportamento poluidor, adquirido e mantido em função das contingências econômicas que reforçam tal comportamento - basicamente, menores custos e maiores lucros para as indústrias poluentes e maior oferta e melhores preços para os consumidores dos respectivos produtos. Temos, então, a pseudocontingência entre o comportamento poluidor e a consequente poluição ambiental, extremamente prejudicial à sobrevivência e reprodução de toda a comunidade, porém incapaz de por si só punir o comportamento poluidor. $\mathrm{O}$ terceiro elemento do modelo corresponde à contingência entre $\mathrm{o}$ descontentamento popular ocasionado pelas consequências socialmente indesejáveis da poluição ambiental e o comportamento de punir os comportamentos causadores dessa poluição. Tal descontentamento popular é aversivo para os membros eletivos do governo - no caso brasileiro, membros dos poderes Executivo e Legislativo -, reforçando negativamente, por essa razão, o comportamento dos mesmos de punir o comportamento poluidor, mediante a 
edição e aplicação de normas jurídicas. Por fim, temos a contingência punitiva representada pela norma jurídica que pune - isto é, torna menos provável - o comportamento poluidor.

Outro exemplo, muito conhecido de nós brasileiros, é a legislação anti-inflacionária. Segundo muitos economistas, a causa principal da inflação é a emissão de moeda em excesso para financiar os gastos governamentais (MANKIW, 2008). Podemos, então, interpretar a legislação anti-inflacionária com base no nosso modelo, nos seguintes termos.

O comportamento inflacionário do governo é reforçado pelos destinatários dos recursos financiados com a emissão de moeda em excesso. Essa quantidade excessiva de moeda gera o aumento geral dos preços, ou seja, inflação, que é prejudicial à sobrevivência e reprodução da sociedade como um todo. A inflação afeta drasticamente o nível de vida dos assalariados e outras pessoas, como os aposentados, que não têm como aumentar seus ganhos ao ritmo da inflação, gerando descontentamento político, o qual é aversivo para os membros eletivos do governo. O descontentamento popular reforça negativamente, então, o comportamento dos membros eletivos do governo de proibir o financiamento dos gastos governamentais por meio da emissão excessiva de moeda, o qual, por sua vez, controla punitivamente o comportamento inflacionário.

Para finalizar, cabe observar que, como ocorre com todas as ciências históricas, é difícil se testar um modelo sociológico-evolucionário como o apresentado nesta seção. Não obstante, ele não é de todo imune ao teste empírico, bastando para tal se obter evidências de que discussões envolvendo as consequências prejudiciais à sobrevivência e reprodução da sociedade de determinados comportamentos tiveram um papel relevante por ocasião da instituição ou modificação de normas jurídicas visando ao controle punitivo dos mesmos. Por outro lado, além desse uso descritivo ou interpretativo, o modelo também tem um uso prescritivo potencial, no sentido de se prestar à avaliação de normas jurídicas vigentes (inclusive de sua interpretação doutrinária e jurisprudencial), sob o ponto de vista da contribuição para a sobrevivência e reprodução da sociedade como um todo.

\section{CONCLUSÃO}

Concebida como processo social internalizado, ou seja, que não depende da extinção dos grupos humanos, mas apenas das práticas culturais por eles adotadas, a seleção sociocultural humana tem por base uma complexa combinação de contingências sociais que, em conjunto, perfazem o que eu chamei de contingências sociais de segundo grau. 
No caso do sistema jurídico, essas contingências sociais de segundo grau são responsáveis pela seleção das normas jurídicas, entendidas enquanto contingências sociais punitivas que controlam os comportamentos considerados socialmente indesejáveis em um dado momento da história de um determinado grupo social humano.

O modelo mais simples de contingência social de segundo grau compõe-se de quatro contingências comportamentais entrelaçadas cujo resultado combinado é a emergência, manutenção ou modificação de uma dada norma jurídica. Esse entrelaçamento de contingências comportamentais se dá principalmente por meio das organizações jurídicas especializadas - no caso dos Estados modernos, basicamente os órgãos dos poderes executivo, legislativo e judiciário.

Cabe frisar que o processo de seleção sociocultural descrito neste artigo está longe de ser um mero análogo do processo de seleção natural ou mesmo da seleção comportamental operante. Por exemplo, nada impede que atuemos de forma deliberada no sentido de buscar dirigir o processo de seleção sociocultural, observadas, claro, as limitações derivadas da alta complexidade dos processos comportamentais coletivos (SKINNER, 1971, 1981; DAWKINS, 1989; MALOTT, 2009; ACEMOGLU, ROBINSON, 2012; SCHNEIDER, 2012). De fato, como observa Skinner (1971), se existe algo que possa ser retrospectivamente considerado como uma direção comum dos processos evolucionários tal é certamente a crescente sensibilidade às consequências do comportamento individual. No caso dos seres humanos, tal sensibilidade, aliada a outras características da espécie, particularmente a capacidade de comunicação verbal, deu origem à cultura, ou seja, ao controle do comportamento individual pelo grupo social, a qual, permitindo às sociedades humanas se diferenciarem em sistemas sociais voltados ao cumprimento de funções vitais à sua sobrevivência e reprodução, possibilitou aos seres humanos adaptar seu comportamento a contingências que, na maioria, senão na totalidade, das outras espécies animais, somente atuam por meio do longo e custoso processo de seleção natural.

Nesse contexto, o direito cumpre certamente um papel fundamental, o qual, eu acredito, pode ficar muito melhor explicado a partir de uma abordagem evolucionária como a que foi esboçada neste artigo.

\section{REFERÊNCIAS}

ACEMOGLU, D.; ROBINSON, J. A. Why nations fail: the origins of power, prosperity, and poverty. New York: Crown, 2012. 
BAUM, W. M. Being concrete about culture and cultural evolution. In: THOMPSON, N.; TONNEAU, F. (Ed.). Perspectives in ethology: evolution, culture, and behavior. New York: Kluwer Academic/Plenum Publishers, 2001.

. Rules, culture, and fitness. The Behavior Analyst, v. 18, n. 1, 1995. p. 1-21.

. The trouble with time. In: HAYES, L. J.; GHEZZI, P. M. (Ed.). Investigations in behavioral epistemology. Reno: Context Press, 1997.

. Understanding behaviorism: behavior, culture and evolution. $2^{\text {nd }}$. ed. Oxford: Blackwell, 2005.

.; RACHLIN, H. Choice as time allocation. Journal of the Experimental Analysis of Behavior, n. 12, 1969. p. 861-74.

BLACK, D. The behavior of law. London: Academic Press, 1976.

BRASIL. Decreto-lei n ${ }^{\circ} 2848$, de 7 de dezembro de 1940. Código Penal. Diário Oficial da União, Rio de Janeiro, 31 dez. 1940. Disponível em: $<$ http://www.planalto.gov.br/ccivil_03/decreto-lei/Del2848compilado.htm>. Acesso em: 19 abr. 2014.

CAMPBELL, D. T. Evolutionary epistemology. In: SCHILPP, P. A. (Ed.). The philosophy of Karl R. Popper. La Salle: Open Court, 1974.

CATANIA, A. C. Learning. $4^{\text {th }}$. ed. Upper Saddle River: Prentice Hall, 1998.

DAWKINS, R. The selfish gene. New York: Oxford University Press, 1989.

DONAHOE, J. W.; PALMER, D. C. Learning and complex behavior. Richmond, MA: Ledgetop, 2004.

DURKHEIM, E. The division of labor in society. Translated by G. Simpson. New York: Free Press, 1964.

DUXBURY, N. Patterns of American jurisprudence. Oxford: Oxford University Press, 1995.

FRIEDMAN, L. M. A history of American law. $2^{\text {nd }}$. ed. New York: Touchstone, 1985.

GLENN, S. S. Rules as environmental events. The Analysis of Verbal Behavior, v. 5, 1987. p. 29-32.

.; MALOTT, M. E. Complexity and selection: implication for organizational change. Behavior and Social Issues, v. 13, 2004. p. 89-106.

GRANT, B. S. Fine tuning the peppered moth paradigm. Evolution, v. 53, n. 3, 1999. p. 9804.

HARRIS, M. Our kind: who we are, where we came from, where we are going. New York: HarperPerennial, 1990. 
HEDSTRÖM, P. Dissecting the social: on the principles of analytical sociology. Cambridge, UK: Cambridge University Press, 2005.

KELSEN, H. General theory of law and state. Translated by Anders Wedberg. Cambridge, MA: Harvard University Press, 1945. Press, 1967.

Pure theory of law. Translated by M. Knight. Berkeley: University of California

LAMAL, P. A. (Ed.). Behavioral analysis of societies and cultural practices. Bristol: Hemisphere Publishing Corporation, 1991.

LEVITT, S. D. The effect of prison population size in crime rates: evidence from prison overcrowding litigation. The Quarterly Journal of Economics, v. 111, n. 2, 1996. p. 319-51.

LOWENKRON, B. An introduction to joint control. The Analysis of Verbal Behavior, v. 22, 2006. p. 123-7.

. Some logical functions of joint control. Journal of the Experimental Analysis of Behavior, v. 69, n. 3, 1998. p. 327-54.

LUHMANN, N. A sociological theory of law. Translated by E. King and M. Albrow. London: Routledge and Kegan Paul, 1985.

. Essays on self-reference. New York: Columbia University Press, 1990.

. Social systems. Stanford: Stanford University Press, 1995.

. The differentiation of society. Translated by S. Holmes and C. Larmore. New York: Columbia University Press, 1982.

MAJERUS, M. E. N. Melanism: evolution in action. Oxford: Oxford University Press, 1998.

MALOTT, M. E. The paradox of organizational change: engineering organization with behavioral systems analysis. Reno, NV: Context Press, 2003.

MALOTT, R. W. Principles of behavior. $6^{\text {th }}$. ed. Upper Saddle River: Pearson Education, 2009.

MANKIW, N. G. Principles of economics. $5^{\text {th }}$. ed. Mason, OH: South-Western Cengage Learning, 2008.

MAYNARD SMITH, J. Evolution and the theory of games. Cambridge: Cambridge University Press, 1982.

MAYR, E. O desenvolvimento do pensamento biológico: diversidade, evolução e herança. Tradução Ivo Martinazzo. Brasília: UnB, 1998.

. What evolution is. London: Phoenix, 2002. 
MICHAEL, J. L. Concepts and principles of behavior analysis. Kalamazoo: Association for Behavior Analysis, 2004.

Distinguishing between discriminative and motivating functions of stimuli. Journal of the Experimental Analysis of Behavior, v. 37, n. 1, 1982. p. 149-55.

Establishing operations. The Behavior Analyst, v. 16, n. 2, 1993. p. 191-206.

Evocative and repertoire-altering effects of an environmental event. The Analysis of Verbal Behavior, v. 2, 1983. p. 19-21.

MOELLER, H-G. Luhmann explained: from souls to systems. La Salle: Open Court, 2006.

MOORE, J. Conceptual foundations of radical behaviorism. Cornwall-on-Hudson, NY: Sloan, 2008.

NORTH, D. C. Institutions, Institutional change and economic performance. New York: Cambridge University Press, 1990.

. Structure and change in economic history. New York: Norton, 1981.

PALMER, D. C. Chomsky's nativism: a critical review. The Analysis of Verbal Behavior, v. 17, 2000. p. 39-50.

. Selectionist constraints on neural networks. In: DONAHOE, J. W.; DORSEL, V. P. (Ed.). Neural-networks models of cognition. Amsterdam: Elsevier, 1997.

. The speaker as listener: the interpretation of structural regularities in verbal behavior. The Analysis of Verbal Behavior, n. 15, 1998. p. 3-16.

PATERSON, J. Reflexive law: challenges and choices. In: CALLIESS, G-F. et al. (Ed.). Festschrift für Gunther Teubner zum 65. Geburtstag am 30. Berlin: De Gruyter Recht, 2009.

.; TEUBNER, G. Changing maps: empirical legal autopoiesis. Social and Legal Studies, v. 7, 1998. p. 451-86.

PEAR, J. J. The science of learning. Philadelphia, PA: Psychology Press, 2001.

POSNER, R. A. Law, pragmatism, and democracy. Cambridge, MA: Harvard University Press, 2003.

RACHLIN, H. Introduction to modern behaviorism. $3^{\text {rd }}$. ed. New York: W. H. Freeman, 1991.

RODRÍGUEZ, D.; ARNOLD, M. Sociedad y teoria de sistemas: elementos para la comprensión de la teroría de Niklas Luhmann. Santiago: Universitaria, 2007.

ROSSI, P. I filosofi e le machine 1400-1700. Milano: Feltrinelli, 1962. 
SCHNEIDER, S. M. The science of consequences: how they affect genes, change the brain, and impact our world. Amherst, N.Y.: Prometheus Books, 2012.

SIDMAN, M. Coertion and its fallout. Boston: Authors Cooperative, 1989.

SKINNER, B. F. About behaviorism. New York: Vintage Books, 1976.

. Beyond freedom and dignity. New York: Knopf, 1971.

. Canonical papers of B. F. Skinner. In: CATANIA, A. C.; HARNAD, S. (Ed.). The selection of behavior: the operant behaviorism of B. F. Skinner: comments and consequences. New York: Cambridge University Press, 1988.

. Contingencies of reinforcement: a theoretical analysis. New York: AppletonCentury-Crofts, 1969.

. Reflections on behaviorism and society. Englewood Cliffs: Prentice-Hall, 1978.

. Science and human behavior. New York: Free Press, 1953.

. Selection by consequences. Science, v. 213, 1981. p. 501-4.

. The behavior of organisms: an experimental analysis. New York: Appleton-CenturyCrofts, 1938.

- The behavior of the listener. In: HAYES, S. C. (Ed.). Rule-governed behavior: cognition, contingencies \& instructional control. Reno, NV: Context Press, 1989.

. Verbal behavior. New York: Appleton-Century-Crofts, 1957.

SOLTIS, J.; BOYD, R.; RICHERSON, P. J. Can group-functional behaviour evolve by cultural group selection? An empirical test. Current Anthropology, v. 36, n. 3, 1995.

TAMANAHA, B. Z. A non-essentialist version of legal pluralism. Journal of Law and Society, v. 27, n. 2, 2000. p. 296-321.

. The internal/external distinction and the notion of a 'practice' in legal theory and sociolegal studies. Law \& Society Review, v. 30, n. 1, 1996. p. 163-204.

TEUBNER, G. Evolution of autopoietic law. In: Teubner, G. (Ed.). Autopoietic law: a new approach to law and society. Berlin: de Gruyter, 1988.

. Law as an autopoietic system. Oxford: Blackwell, 1993.

TODOROV, J. C. Laws and the complex control of behavior. Behavior and Social Issues, v. 14, 2005. p. 86-91.

. Quem tem medo da punição? Revista Brasileiro de Terapia Comportamental e Cognitiva, v. 3, n. 1, 2001. p. 37-40. 
WATSON, A. The evolution of law. Baltimore: The Johns Hopkins University Press, 1985.

WEBER, M. Economy and society. Berkeley: University of California Press, 1968.

WILSON, D. S. Human groups as adaptive units: towards a permanent consensus. In: CARRUTHERS, P.; LAURENCE, S.; STICH, S. The innate mind. Oxford: Oxford University Press, 2006.

\section{STEPS TOWARDS AN EVOLUTIONARY APPROACH TO LAW}

ABSTRACT: The article puts forward some fundamental ideas for the development of an evolutionary approach to law based on the radical behaviorist concept of a social system as a web of interlocked behavioral patterns. After discussing the three levels of behavioral evolution, namely phylogenetic, ontogenetic and sociocultural, the article explains how the emergence of a functionally specialized legal system based on legal organizations was able to internalize the process of legal evolution through the selection of legal norms by means of second-order legal contingencies.

KEYWORDS: Radical behaviorism. Second-order social contingency. Social system. Sociocultural selection. 